\title{
MODAL SOSIAL DAN PERSEPSI TIK DALAM PEMBANGUNAN DESA PERBATASAN
}

\author{
Vience Mutiara Rumata ${ }^{1}$, Olivia Nelar ${ }^{2}$, Awit Marwati Sakinah ${ }^{3}$ \\ ${ }^{1,2}$ Pusat Penelitian dan Pengembangan Aplikasi Informatika dan Informasi dan Komunikasi Publik Kementerian \\ Komunikasi dan Informatika \\ Jl. Medan Merdeka Barat No. 9B, Jakarta Pusat, 10110, Indonesia \\ ${ }^{3}$ STMIK Tasikmalaya \\ ${ }^{3}$ Jl. R.E. Martadinata No. 272A, Panyingkiran, Indihiang, Tasikmalaya, Jawa Barat, 46151, Indonesia \\ No. Telp./HP: ${ }^{1} 08111077882,{ }^{2} 082116329990,{ }^{3} 085722626922$ \\ E-mail: ${ }^{1}$ vien001@kominfo.go.id, ${ }^{2}$ oliv001@kominfo.go.id, ${ }^{3}$ awitsakinah@gmail.com
}

\section{SOCIAL CAPITAL AND PERCEPTION TOWARD THE ICT IMPACTS ON VILLAGE DEVELOPMENT IN BORDER AREA}

\begin{abstract}
This is an explanatory research which aims to find out the relationship between social capital - bridging and bonding - to the perception on ICT for rural community in the border area. This study uses quantitative method by using questionnaires in Kifu Village, Kupang Regency, East Nusa Tenggara. The systematic random sampling method was applied in the population of adolescent aged 16-18 years old. The result is that bridging and bonding social capital has a significant effect on the perception on ICT for rural development with 22 values of $33.2 \%$. Non-social capital factor such as internet self-efficacy has impact on youth perception toward ICT for rural development.
\end{abstract}

Keywords: capital social, perception, ICT, integrated broadband village.

\begin{abstract}
Abstrak. Penelitian ini bersifat eksplanatori dengan tujuan untuk mengetahui modal sosial, yaitu bridging dan bonding terhadap persepsi TIK dalam pembangunan desa perbatasan. Populasi penelitian yaitu remaja dengan usia pada rentang 16 sampai 18 tahun di Desa Kifu, Kabupaten Kupang, Nusa Tenggara Timur. Penelitian menggunakan pendekatan kuantitatif dengan metode analisis jalur. Teknik pengumpulan data penelitian dilaksanakan melalui penyebaran kuesioner secara systematic random sampling. Hasil penelitian menunjukkan bahwa aspek hipotesis diterima yaitu bridging dan bonding modal sosial memiliki pengaruh yang signifikan terhadap persepsi TIK bagi pembangunan desa dengan nilai R2 sebesar 33,2\%. Faktor-faktor non-modal sosial juga memengaruhi persepsi para remaja tersebut terhadap TIK dan dampaknya bagi pembangunan desa, misalnya faktor efikasi diri ketika menggunakan internet.
\end{abstract}

Kata kunci: modal sosial, persepsi, TIK, desa broadband terpadu. 


\section{PENDAHULUAN}

Perkembangan Teknologi Informasi dan Komunikasi (TIK) telah memberikan dampak yang fundamental bagi perkembangan masyarakat, termasuk bagi pembangunan masyarakat desa. TIK diyakini berpotensi membantu capaian-capaian pembangunan sosial, ekonomi, budaya, dan politik masyarakat. pada awal 1980an, International Telecommunication Union (ITU) melakukan studi yang mengaitkan antara penggunaan TIK dan dampaknya bagi pembangunan. Hasilnya adalah perkembangan TIK memberikan manfaat dalam bidang kesehatan, pelayanan sosial, administrasi dan perdagangan, pertumbuhan ekonomi, serta meningkatkan kualitas hidup (Maitland dalam Hamel, 2010). Temuan ini menjadi landasan program 'ICT4D' (TIK untuk Pembangunan) yang diinisiasi oleh $\mathrm{PBB}$, melalui program pembangunan PBB (UNDP) selama kurang lebih dua dekade belakangan ini.

Manfaat TIK dapat terwujud secara merata, apabila kesenjangan digital di berbagai wilayah geografis dapat diatasi. Di berbagai negara di dunia, pembangunan fisik infrastruktur TIK merupakan pendekatan utama pemerintah dalam meminimalisasi kesenjangan digital. Sebagai contoh, Pemerintah Botswana meluncurkan kebijakan "Connectivity Communities", yang salah satu programnya adalah pembangunan Pusat Akses Komunitas (Community Access Centers/CAC) di wilayah perdesaan (Gatsha \& Masalela, 2012). Pembangunan pusat akses juga dilakukan oleh Pemerintah Nepal, bekerja sama dengan United Nations Development Programme (UNDP), yaitu membangun Rural Information Center yang berfungsi sebagai fasilitas TIK bagi masyarakat desa (Harris et al., 2003).

Beberapa program tersebut pernah diadopsi dalam kebijakan nasional di Indonesia. Pembangunan pusat informasi Telecenter pernah dijalankan Kementerian Perencanaan Pembangunan Nasional (Bappenas) bekerja sama dengan UNDP di enam provinsi di Indonesia pada tahun 2005. Akan tetapi, program ini tidak dilanjutkan. Sepuluh tahun kemudian, Kementerian Komunikasi dan Informatika (Kemkominfo) bekerja sama dengan Balai Penyedia dan Pengelola Pembiayaan Telekomunikasi dan Informatika (BP3TI) meluncurkan program 'Desa Broadband Terpadu' (DBT) (Kementerian Komunikasi dan Informatika, 2015).

DBT merupakan satu dari lima program yang diluncurkan Kemkominfo untuk mengurangi kesenjangan digital di wilayah NKRI (Balai Penyedia dan Pengelola Pembiayaan Telekomunikasi dan Informatika, 2016). Pelaksanaan program DBT terbagi menjadi empat fase, yaitu:

- Fase I sasaran pembangunan di 50 desa (2015);

- Fase II dengan sasaran pembangunan di 500 desa (2016);

- Fase III dengan sasaran pembangunan di 50 desa; dan

- Fase IV sasaran pembangunan di 500 desa (pertengahan 2017 hingga akhir 2018) (Direktorat Pengembangan Pita Lebar PPI Kemkominfo dalam Hamjen, 2016).

Program DBT memilki empat komponen yaitu: aplikasi, device, network, dan pendampingan untuk mendukung kegiatan, utamanya, ekonomi masyarakat yang tinggal di desa kategori 'tertinggal, terdepan dan terluar' (3T) (Al Ayyubi, 2016).

Salah satu penerima bantuan program DBT adalah Desa Kifu, Kecamatan Amfoang Timur, Kabupaten Kupang, Provinsi Nusa Tenggara Timur. Desa Kifu merupakan desa yang terletak di perbatasan Indonesia - Timor Leste dan berjarak kurang lebih 199,6 km dari Kota Kupang. Desa yang memiliki luas wilayah sebesar $9,33 \mathrm{~km}$ persegi ini didiami oleh setidaknya 1.523 jiwa pada Desember 2015 (Desa Kifu, 2016). Tingkat pendidikan masyarakat desa ini cukup rendah (Tabel 1). Desa Kifu menerima bantuan DBT pada fase pertama yaitu tahun 2015. Penyedia jaringan desa ini adalah Telkom dengan kapasitas link sebesar 2 Mbps dengan IP Address 103.37.225.141/30, dengan status 'aktif' (Hamjen, 2016).

Pengintegrasian TIK dalam programprogram pembangunan di level nasional, tidak selalu menitikberatkan pada penyediaan infrastruktur fisik untuk akses internet semata. Regulator juga perlu memperhatikan 
faktor nonfisik demi mempertahankan keberlanjutan program-program tersebut. Faktor nonfisik yang menjadi perhatian utama adalah faktor sosial, yaitu salah satunya adalah modal sosial. Modal sosial menjadi perhatian ilmuwan sosiologi, salah satunya Pierre Bourdieu yang mengembangkan konsep tersebut sejak tahun 1970an. Kata "modal sosial" menjadi populer pada akhir 1990an. Dalam bukunya "Bowling Alone", Putnam (2000) berpendapat bahwa modal sosial merujuk pada hubungan antaranggota komunitas bisa berbentuk jaringan sosial, norma, hubungan timbal balik, dan kepercayaan. Pemberdayaan manusia, berupa pendampingan kepada anggota komunitas yang menerima bantuan pembangunan fisik TIK tersebut, memang penting. Akan tetapi, kolaborasi dalam struktur dan jaringan sosial komunitas dapat membuat pembangunan menjadi berkelanjutan. Setidaknya ada tiga mekanisme pengelolaan potensi desa: 1) mekanisme pemberdayaan (empowering) berupa partisipasi dan kesiapan sosial; 2) mekanisme directing (pembangunan infrastruktur fisik); dan 3) mekanisme supporting (kemitraan antara pemerintah dan nonpemerintah dalam pengelolaan) (Usman, 2016). Lebih lanjut disebutkan bahwa mekanisme pemberdayaan memberi peluang sebesar-besarnya bagi warga desa untuk memformulasikan dan menjalankan program yang nantinya didukung oleh penggunaan TIK. TIK dalam mekanisme ini, memfasilitasi pertukaran informasi dan transaksi serta memperluas jaringan sosial antarwarga desa (Usman, 2016).
Belum banyak penelitian dilakukan terkait pembangunan masyarakat desa yang menerima bantuan DBT hingga saat ini. Jikapun ada, penelitian terdahulu terkait program ini kurang memperhatikan dimensi sosial. Hamjen (2016) mengukur efektivitas perangkat dengan menggunakan metode analisis kepentingan kinerja dan uji statistik Chi Square, di 50 desa penerima bantuan DBT tahap I tahun 2015. Usman (2016) meneliti mekanisme pengelolaan potensi desa dalam program DBT dari perspektif masyarakat desa, pelaku usaha dan pemerintah. Karena itu, penelitian ini memfokuskan pada dimensi sosial dengan pertanyaan penelitian sebagai berikut: "Bagaimana pengaruh modal sosial yaitu bridging dan bounding terhadap persepsi fungsi TIK dalam pembangunan desa?"

$$
\text { Penelitian ini menyumbang }
$$
keberagaman penelitian-penelitian sosial khususnya yang terkait dengan program pembangunan infrastruktur pemerintah di wilayah perbatasan. Keluaran dari penelitian ini tidak saja sekadar ketersediaan data, tetapi juga gambaran persepsi para remaja di era TIK serta dampaknya terhadap pembangunan desa perbatasan di Indonesia. Signifikansi penelitian ini dari segi praktis adalah memberikan rekomendasi bagi para pemangku kebijakan khususnya Kementerian Komunikasi dan Informatika (Kemkominfo); Balai Penyedia dan Pengelola Pembiayaan Telekomunikasi dan Informatika (BP3TI); serta stakeholders lainnya yang terlibat dalam program DBT ataupun program sejenisnya.

Tabel 1

Jumlah Penduduk Desa Kifu Berdasarkan Pendidikan yang Ditamatkan

\begin{tabular}{llcccc}
\hline \multirow{2}{*}{ No } & \multirow{2}{*}{ Pendidikan yang ditamatkan } & \multicolumn{2}{c}{$\mathbf{2 0 1 5}$} & \multicolumn{2}{c}{$\mathbf{2 0 1 6}$} \\
\cline { 3 - 6 } & & $\mathbf{Q}$ & Persen & Q & Persen \\
\hline 1 & Tidak/belum pernah sekolah & 386 & $(27,59 \%)$ & 412 & $(27,41 \%)$ \\
2 & Tidak/belum tamat SD & 243 & $(17,36 \%)$ & 245 & $(16,30 \%)$ \\
3 & SD & 435 & $(31,09 \%)$ & 462 & $(30,73 \%)$ \\
4 & SLTP/sederajat & 152 & $(10,86 \%)$ & 165 & $(10,97 \%)$ \\
5 & SLTA & 121 & $(16,92 \%)$ & 134 & $(8,91 \%)$ \\
6 & Akademi/Universitas & 62 & $(4,43 \%)$ & 85 & $(5,65 \%)$ \\
\hline Jumlah & $\mathbf{1 3 9 9}$ & \multicolumn{3}{c}{$\mathbf{1 5 0 3}$} \\
\hline
\end{tabular}

Sumber: RPJM Desa Kifu Tahun 2016-2019 hal 12 


\section{LANDASAN KONSEP}

\section{Modal Sosial Kalangan Remaja}

Salah satu dimensi sosial yang menjadi fokus penelitian pembangunan masyarakat adalah modal sosial. Teori modal sosial tidak saja digunakan untuk meneliti struktur sosial, akan tetapi memberikan pandangan yang lebih luas terkait kehidupan sosial bermasyarakat. Modal sosial membantu kita memahami bagaimana intensitas dan konfigurasi interaksi antarindividu di dalam jaringan sosial (Díaz Andrade \& Urquhart, 2009). Setidaknya ada dua pandangan besar terkait definisi modal sosial: konsep yang ditawarkan oleh Pierre Bourdieu serta konsep yang ditawarkan oleh James Coleman dan Robert Putnam (Billett, 2012). Konsep modal sosial menurut Bourdieu (1986) adalah jumlah dari sumber-sumber (resources) baik nyata maupun virtual, yang diterima baik oleh individu maupun kelompok sebagai akibat dari ketahanan jaringan hubungan pribadi dan kelompok. Coleman menggambarkan modal sosial sebagai sebuah akumulasi hubungan antarpersonal dan dapat mendorong kegiatankegiatan yang konstruktif antarpersonal dalam jaringan sehingga secara konseptual diparalelkan pada modal manusia, modal fisik, dan modal keuangan (Coleman dalam Guo, Li \& Ito, 2014). Sedangkan, Putnam berpendapat bahwa jaringan sosial, norma yang bersifat timbal balik, serta kepercayaan merupakan komponen utama pembentuk modal sosial (Putnam, 2000). Dari dua sudut pandang besar ini juga memunculkan dua pandangan berbeda yaitu: pandangan modal sosial sebagai 'private goods' (Bourdieu, 1986) dan modal sosial sebagai 'collective' (Coleman dalam Guo, Li \& Ito, 2014).

Konsep 'modal sosial' itu sendiri telah berkembang di kalangan ilmuwan sosiologi, sehingga definisinya pun beragam. Namun, yang perlu digarisbawahi bahwa modal sosial merupakan sesuatu yang melekat pada struktur hubungan sosial, bukan pada aktor sosial maupun infrastruktur fisik sosial. Modal sosial tidak sekadar menggambarkan karakteristik hubungan sosial di dalam kelompok tertentu, tetapi juga dampaknya terhadap dimensi yang lain termasuk difusi informasi. Adler \& Kwon mendefinisikan modal sosial sebagai itikad baik individu dan kelompok, yang memengaruhi aliran informasi, pengaruh dan solidaritas di dalam jaringan (Adler \& Kwon dalam Díaz Andrade \& Urquhart, 2009). Putnam berpendapat bahwa kelompok sosial inklusif atau disebut "weak-ties" cenderung lebih baik dalam membangun hubungan dengan 'dunia luar' dan difusi informasi baik di dalam maupun keluar kelompok (Putnam, 2000).

Terdapat dua dimensi di dalam konsep modal sosial: bonding social capital dan bridging social capital. Kedua dimensi ini menggambarkan kekuatan atau keeratan hubungan dalam jaringan sosial. Bonding social capital memiliki ikatan hubungan yang jauh lebih kuat dan erat dibandingkan dengan bridging social capital (Guo, Li \& Ito, 2014). Perbedaan karakteristik antara bridging social capital dan bonding social capital dapat dilihat pada Tabel 2.

Tabel 2

Karakteristik Bonding Social Capital dan Bridging Social Capital

\begin{tabular}{cll}
\hline No & \multicolumn{1}{c}{ Bonding Social Capital } & \multicolumn{1}{c}{ Bridging Social Capital } \\
\hline 1 & $\begin{array}{l}\text { Strong-Ties Networks (Kelompok Sosial } \\
\\
\end{array}$ & Eksklusif). \\
2 & $\begin{array}{l}\text { Kelompok bersifat Homogen (anggota kelompok Networks (Kelompok Sosial Inklusif). } \\
\text { dengan latar belakang, minat, demografi yang }\end{array}$ & Kelompok bersifat Heterogen (anggota kelompok dengan \\
& latar belakang, minat, demografi yang beragam).
\end{tabular}
cenderung mirip atau sama). 
tinggi.

4 Jaringan sosial cenderung lebih sempit.

5 Modal sosial yang dimiliki orang-orang yang ada di dalam kelompok (intra-community social capital).

6 Modal sosial dalam konteks ide, relasi, dan perhatian yang berorientasi ke dalam (inward looking).
Jaringan sosial cenderung lebih luas.

Modal sosial yang dimiliki orang-orang yang ada di dalam kelompok dengan orang-orang yang ada di luar kelompok (extra-community social capital).

Memberikan kontribusi bagi perkembangan pembangunan dengan melakukan kontak dan interaksi dengan kelompok di luarnya (outward looking).

Sumber: diolah oleh peneliti dari berbagai sumber.

Melihat karakteristik serta definisi konsep kedua dimensi modal sosial tersebut, maka sudah sewajarnya bila modal sosial lebih banyak ditemukan di masyarakat perdesaan dibandingkan dengan masyarakat perkotaan. Ini merupakan anggapan yang umum. Sørensen melakukan survei untuk mengukur dimensi media sosial di wilayah kota dan desa di Denmark. Studinya menemukan bahwa orang desa dan orang kota memiliki alasan berbeda untuk membangun baik itu bridging dan bonding modal sosial (Sørensen, 2016). Orang desa memiliki alasan sosial (lebih mudah membangun bonding dengan orang desa yang telah lama tinggal di wilayah tersebut). Orang kota lebih memiliki alasan ekonomi (co. pendapatan) ketika membangun modal sosial di dalam kelompoknya (Sørensen, 2016). Sørensen menyarankan bahwa program pembangunan jangan terlalu menitikberatkan pada membangun kohesivitas komunitas, kecuali di wilayah yang bonding modal sosialnya rendah, serta mendorong lebih banyak interaksi antarkomunitas-komunitas lain.

Wiesinger (2007) berpendapat bahwa keberadaan modal sosial di dalam suatu masyarakat memiliki peran yang sangat penting bagi perkembangan desa tersebut serta bisa berdampak terhadap pengurangan kadar marginalitas di desa.

\section{Modal Sosial, TIK dan Pembangunan Desa}

Wiesinger menguji peran modal sosial terhadap perkembangan desa (Gambar 1) di tiga purwarupa desa terpencil di Austria.
Ketiga desa ini diklasifikasikan berdasarkan distribusi modal sosial, modal ekonomi, dan modal budaya/intelektual. Sebagai ilustrasi, desa terpencil A memiliki tingkat modal ekonomi dan modal budaya relatif rendah (co. tingkat pendidikan formal rendah, migrasi keluar desa) tapi memiliki modal sosial yang relatif tinggi (co. kepercayaan timbal balik yang tinggi, norma-norma yang kuat di masyarakat). Temuannya bahwa kebijakan pemerintah dapat berperan ganda baik itu positif maupun negatif. Positif apabila kebijakan tersebut dapat menumbuhkan kepercayaan antara aktoraktor yang berperan di desa. Negatif apabila kebijakan pemerintah justru menghancurkan fundamental dari modal sosial tersebut. Contohnya apabila pemerintah menghapus program Posyandu, kemungkinan akan menganggu ikatan sosial antarwarga.

Modal sosial dan hasil yang diharapkan oleh masyarakat desa berada di ranah persepsi. Karenanya, penerimaan warga terhadap kondisi atau situasi yang ada di wilayahnya sangat krusial dan berpengaruh terhadap pembentukan modal sosial. Kondisi negatif seperti kemiskinan, lingkungan terpencil dan perasaan 'diabaikan' oleh pemerintah, dapat melemahkan modal sosial. Sebaliknya, bila kondisi lingkungannya makmur atau sejahtera dapat menguatkan modal sosial itu sendiri (Wiesinger, 2007). Tidak hanya itu, modal sosial khususnya bonding dapat menstimulasi tindakan kolektif untuk dapat merespon situasi di luar masyarakat, termasuk merespon situasi pembangunan infrastruktur di perdesaan, termasuk 
beradaptasi dengan TIK (Kusumastuti, 2016).

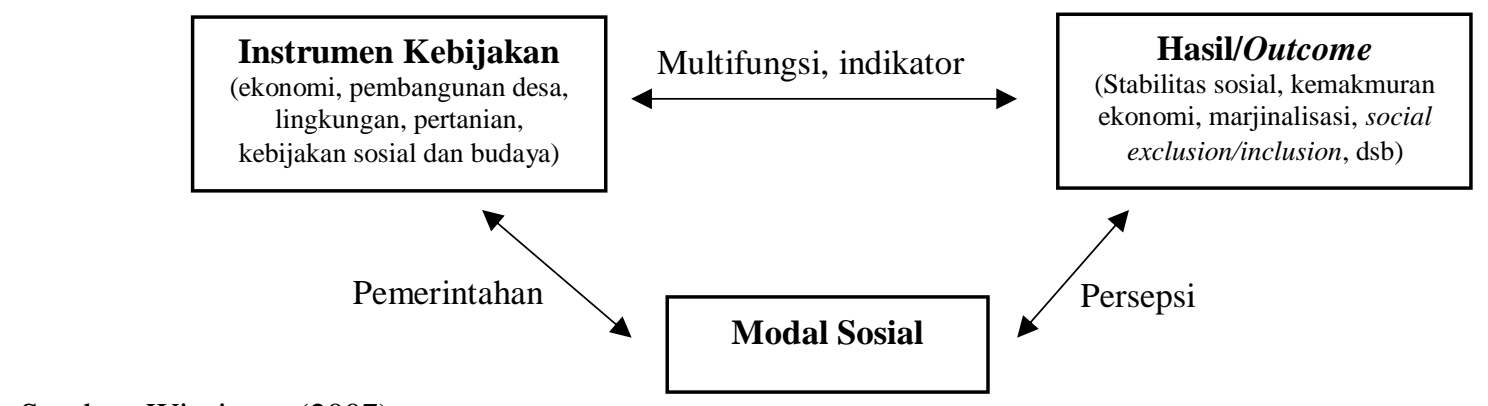

Sumber: Wiesinger (2007)

Gambar 1. Kerangka Konsep Modal Sosial, Instrumen Kebijakan dan Hasil.

Di era TIK di mana pembangunan infrastruktur broadband semakin masif hingga ke wilayah desa terpencil, tentu dapat mengintervensi lingkungan sosial di desa. Intervensi yang dimaksud adalah ketika TIK tidak saja memediasi interaksi sosial, tetapi juga turut berkontribusi terhadap pembangunan desa. Karena itu, penerimaan serta persepsi individu dalam komunitas desa terhadap infrastruktur TIK tersebut sangat berpengaruh. Hal ini berarti bahwa wawasan dan budaya lokal menjadi pertimbangan yang perlu diperhatikan ketika memberi bantuan TIK dalam sebuah wilayah. Intervensi TIK di dalam komunitas sosial juga perlu memperhatikan keterampilan dan wawasan orang lokal serta sumber-sumber di dalam jaringan dan struktur sosial (Díaz Andrade \& Urquhart, 2009). Jadi, kemampuan individu memanfaatkan TIK tidak akan bisa berguna apabila tidak digunakan dalam komunitas yang lebih luas. Kemampuan individu memanfaat TIK di antaranya membuat, mendistribusikan hingga menyimpan informasi. Program pembangunan dan pemberdayaan masyarakat di desa tidak akan dirasakan masyarakat, apabila individu yang memiliki kemampuan TIK tersebut terisolasi secara sosial.

\section{Modal Sosial Pengguna Internet}

Internet telah mengubah pola interaksi sosial manusia dari tatap muka menuju termediasi dengan gawai. Di era web 2.0, setiap individu dapat membangun jaringan dengan individu lain tanpa terbatas ruang dan waktu dengan mudah. Interaksi online dapat meningkatkan modal sosial baik itu bonding dan bridging. Meski demikian, ada dua gagasan kontradiktif terkait dampak internet dengan modal sosial individu penggunanya. Satu sisi, internet memungkinkan individu untuk memperluas jaringan sosialnya sehingga meningkatkan brigding modal sosial (co. Facebook yang memungkinkan seseorang menjalin pertemanan dengan ribuan orang). Namun di sisi lain, internet juga membuatnya terisolasi dari lingkungan sosial di sekitarnya sehingga tingkat bonding modal sosialnya di lingkungan offline dapat berkurang. Meski demikian, Chew dan kolega berpendapat bahwa kontradiktif ini terjadi akibat adanya mekanisme yang berbeda. Interaksi online yang terjadi antaranggota di dalam komunitas yang sama, justru akan meningkatkan attachment dengan sesama anggota komunitas (augmentation effect) (Ei Chew et al., 2011). Demikian sebaliknya, interaksi online dengan orang di luar komunitasnya, justru akan melemahkan keterlibatan individu tersebut di dalam komunitasnya sendiri (displacement effect). Mereka menyakini bahwa mekanisme inilah yang menyebabkan jaringan sosial secara online dapat meningkatkan ataupun mengurangi kadar attachment, khususnya para kaum muda, terhadap lingkungan sosial desanya.

Williams (2006) berpendapat bahwa mengukur modal sosial akibat internet tidak bisa disamakan dengan mengukur modal sosial di era media massa. Tidak seperti 
televisi, internet menyediakan ruang interaktif meskipun TV juga memancing diskusi antaranggota keluarga. Karenanya, dia mencetuskan sebuah skala pengukuran modal sosial di internet atau dikenal dengan sebutan Internet Social Capital Scale (ICSC). ICSC menggabungkan dimensi bonding dan bridging serta offline dan online, dengan mengembangkan konsep modal sosial gagasan Putnam (Putnam, 2000). Hasilnya, ICSC terdiri dari dua subscale: bonding subscale dan bridging subscale yang masing-masing dari subscale tersebut terdapat 10 item pernyataan (Putnam, 2000).

Salah satu item pernyataan bonding subscale: "When I feel lonely, there are several people online/offline I can talk to" (Ketika saya merasa kesepian, masih ada beberapa orang baik yang saya kenal onlineloffline yang bisa saya ajak bicara). Salah satu item pernyataan bridging subscale: "Talking with people online/offline makes me curious about other places in the world" (Berbicara dengan orang baik secara onlineloffline membuat saya penasaran dengan daerah-daerah lain di dunia ini).

Skala ICSC ini pun dikembangkan oleh peneliti ataupun akademisi lainnya dengan menambahkan dimensi lainnya. Hal ini disebabkan bahwa kajian penggunaan internet dan modal sosial tidak saja terjadi pada dimensi garis linear, artinya hanya disebabkan oleh satu faktor atau satu dimensi saja, melainkan multidimensional. Guo dan koleganya (Guo, Li \& Ito, 2014) mengombinasikan alat ukur dua dimensi fungsi penggunaan internet yang diperkenalkan oleh Weiser: Goods-andInformation Acquisition (GIA) dan SocioAffective Regulation (SAR), dengan ICSC untuk mengkaji dampak penggunaan dan fungsi internet terhadap persepsi mahasiswa China di Jepang terhadap modal sosial. Hasilnya, semakin tinggi frekuensi penggunaan internet berdampak negatif terhadap pembentukan dan pertahanan ikatan bonding social capital. Penggunaan internet untuk memenuhi kebutuhan informasi bagi individu, justru berdampak positif terhadap bridging social capital.

Dari penjabaran kerangka konseptual tersebut, maka hipotesis yang akan diuji dalam penelitian ini (Gambar 2) adalah:

- H1: Semakin baik Bonding Modal Sosial, maka semakin baik persepsi fungsi TIK untuk pembangunan Desa Kifu.

- H2: Semakin baik Bridging Modal Sosial, maka semakin buruk persepsi fungsi TIK untuk pembangunan Desa Kifu.

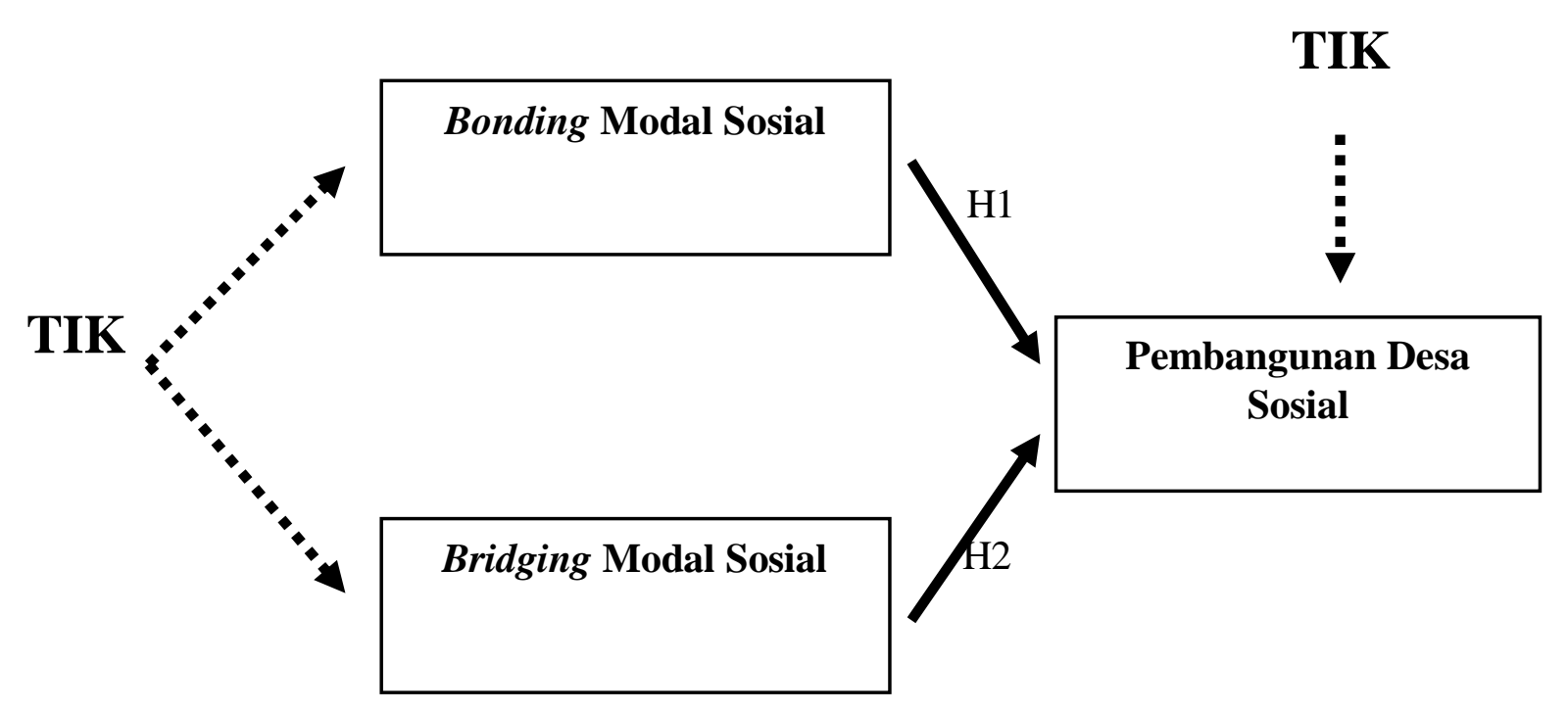

Gambar 2. Kerangka Berpikir Penelitian 


\section{METODE PENELITIAN}

Metode penelitian ini menggunakan metode kuantitatif dengan pendekatan explanatory research (penelitian eksplanatori atau penelitian penjelasan). Menurut Sugiyono, explanatory research merupakan penelitian yang menjelaskan hubungan kausal antara variabel-variabel yang memengaruhi hipotesis (Sugiyono, 2006), penelitian ini memiliki tiga variabel yaitu bonding modal sosial, bridging modal sosial dan TIK untuk pembangunan desanya. Pengujian hipotesis menggunakan analisis jalur (path analysis). Pengumpulan data primer dilakukan dengan cara penyebaran kuesioner. Teknik sampling dilakukan dengan menggunakan metode probability sampling yaitu dengan simple random sampling dan pengambilan responden dilakukan sistematik yaitu melakukan pemilihan secara sistematis berdasarkan list yang diberikan oleh Kepala Desa. Adapun populasi dalam penelitian ini adalah masyarakat Desa Kifu, Kabupaten Kupang, Nusa Tenggara Timur, dengan rincian sebagai berikut (Tabel 3).

Tabel 3

Populasi Masyarakat di Desa Kifu pada Tahun 2016

\begin{tabular}{lllll}
\hline RT/RW & KK & $\mathbf{L}$ & $\mathbf{P}$ & $\mathbf{L + P}$ \\
\hline $001 / 001$ & 45 & 96 & 120 & 216 \\
$002 / 001$ & 46 & 115 & 130 & 245 \\
$003 / 001$ & 26 & 60 & 56 & 116 \\
$004 / 001$ & 30 & 77 & 5 & 82 \\
$005 / 002$ & 36 & 96 & 93 & 189 \\
$006 / 002$ & 44 & 91 & 95 & 186 \\
$007 / 002$ & 36 & 85 & 96 & 181 \\
$008 / 003$ & 24 & 55 & 61 & 116 \\
\hline Total & 287 & 675 & 656 & 1331 \\
\hline
\end{tabular}

Sumber: RPJM Desa Kifu tahun 2016-2019

Jika populasi finit, maka rumus besar sampel adalah

$$
n=\frac{N Z_{1-\alpha / 2}^{2} P(1-P)}{(N-1) d^{2}+Z_{1-\alpha / 2}^{2} P(1-P)}
$$

di mana

$\mathrm{N} \quad=$ besar populasi (1331)

$\mathrm{Z}_{1-\alpha / 2}=$ nilai distribusi normal baku (tabel Z) pada $\alpha$ tertentu

$\mathrm{P} \quad=$ harga proporsi di populasi

$\mathrm{d} \quad=$ kesalahan (absolut) yang dapat ditolerir

Dari rumus tersebut, dengan menggunakan margin of error sebesar $\pm 10 \%$ dan tingkat kepercayaan $90 \%$, didapatkan sampel sebesar 57 responden, adapun sampling kriteria pada penelitian ini adalah remaja dengan rentang usia 16 - 18 Tahun yang tergolong aktif dan produktif dalam menggunakan perangkat TIK. Rentang usia tersebut merupakan bagian apa yang dikenal dengan sebutan "generasi Z" atau "Children of the Digital Age", yaitu generasi yang selalu terkoneksi secara online dan selalu mengakses internet dan media sosial (Nagy, 2017).

Dengan menggunakan $\alpha=5 \%$ sehingga didapat nilai $Z_{\alpha}=1,96$ dan $1-\beta=85 \%$ sehingga didapat nilai $Z_{\beta}=1,04 ; \sigma^{2}=0,5^{2}$ dan $\mathrm{d}=0,2$ 
maka didapat jumlah sampel sebanyak 57 responden.

\section{Operasionalisasi Konsep}

Penelitian ini memiliki tiga variabel yaitu Bonding Modal Sosial, Bridging Modal Sosial dan TIK untuk pembangunan desanya. Untuk Bonding dan Bridging Modal Sosial, Skala ICSC (Williams, 2006) digunakan setelah sebelumnya diterjemahkan ke dalam Bahasa Indonesia dan disederhanakan kalimatnya. Tidak semua item pernyataan pada skala ICSC digunakan, karena pertimbangan konteks kalimat yang tidak sesuai dengan penelitian ini. Sebagai contoh, item pernyataan
Bonding Subscale ICSC adalah: "the people I interact with onlineloffline would help me fight an injustice" (orang-orang dengan siapa saya berinteraksi baik secara online/offline akan membantu saya melawan ketidakadilan) (Williams, 2006), tidak disertakan ke dalam item pernyataan pada penelitian ini. Dimensi ketiga dalam penelitian ini adalah fungsi TIK untuk pembangunan desa. Penelitian ini mengadaptasi literatur-literatur yang membahas dampak TIK terhadap pembangunan desa (Ei Chew et al., 2011; Gregg et al., 2007). Skala ini menggunakan pendekatan Likert 1 (Sangat Tidak Setuju) sampai 5 (Setuju Sekali) (Tabel 4).

Tabel 4

Definisi Operasional Variabel Skala ICSC dan Persepsi TIK terhadap Pembangunan Desa

$\begin{array}{lll}\text { VARIABEL } & \text { ITEM PERNYATAAN } & \text { SKALA } \\ \text { SKALA }\end{array}$

1. Saya percaya kepada beberapa kenalan online saya yang dapat membantu saya untuk menyelesaikan masalah-masalah saya.

2. Saya dapat meminta nasihat, terutama untuk mengambil keputusan penting, kepada teman saya melalui online.

3. Saya tidak membicarakan kehidupan pribadi saya dengan teman secara Ordinal

Bonding

Modal Sosial online.

4. Ketika saya kesepian, saya bisa berbicara dengan teman-teman saya secara online.

5. Ketika saya berinteraksi dengan teman saya secara online, saya mendapatkan informasi terkait pekerjaan.

6. Saya tidak kenal baik dengan teman-teman saya secara online, sehingga saya tidak yakin mereka dapat membantu saya.

1. Berinteraksi dengan orang lain secara online, membantu saya untuk mengetahui dunia di luar desa saya.

2. Berinteraksi dengan orang lain secara online, membuat saya ingin mencoba hal baru.

3. Berinteraksi dengan orang lain secara online, membuat saya tertarik dengan cara berpikir orang yang berbeda suku bahkan berbeda negara dengan saya.

Bridging

Modal Sosial

4. Berbicara dengan orang lain secara online, membuat saya penasaran dengan tempat-tempat di belahan dunia lain.

5. Berinteraksi dengan orang lain secara online, membuat saya menjadi bagian dari komunitas yang lebih besar dari komunitas saya di desa.

6. Berinteraksi dengan orang lain secara online, mengingatkan saya bahwa setiap orang di dunia terkoneksi dengan mudah melalui internet.

7. Saya bersedia menghabiskan waktu saya untuk mendukung kegiatankegiatan komunitas online saya.

8. Berinteraksi dengan orang lain secara online, membuat saya berbicara dengan orang baru setiap hari.
(Menggunakan

Skala Likert

1- 5)

\section{Ordinal (Menggunakan \\ Skala Likert 1- 5)}

\begin{tabular}{lrc}
\hline TIK untuk & 1. Kemampuan mengakses dan mendapatkan informasi dari internet & Ordinal \\
pembangunan & sangat berguna untuk pembangunan desa saya. & (Menggunakan \\
desa & 2. Internet mengancam kekayaan budaya lokal desa saya. & Skala Likert \\
\hline
\end{tabular}




3. Di desa ini, kemampuan warga untuk mencari informasi melalui
internet sangat rendah.
4. Internet dapat membantu warga untuk mencari peluang baru untuk
meningkatkan taraf hidup (ekonomi).
5. Internet mendorong anak muda untuk mencari pekerjaan di luar
desanya.
6. Internet menginsiprasi anak muda agar terlibat serta berperan aktif
dalam mengembangkan desanya.

Sumber: William (2006) serta diolah peneliti

\section{Uji Validitas dan Reliabilitas}

Uji validitas diperlukan untuk mengetahui kelayakan butir-butir suatu daftar atau konstruk pertanyaan dalam mendefinisikan suatu variabel. Pengujian validitas dilakukan dengan menggunakan bantuan software SPSS dengan membandingkan nilai korelasi masingmasing pernyataan dengan $\mathrm{r}$ tabel, di mana pada penelitian ini $\mathrm{r}$ tabel $(\mathrm{N}-2=55)$, yaitu sebesar 0.22 . Jika nilai korelasi lebih besar dari 0.22 , maka pernyataan tersebut dapat dikatakan valid (Tabel 5).

Tabel 5

Hasil Uji Validitas

\begin{tabular}{|c|c|c|c|c|c|c|c|}
\hline Indikator & $\begin{array}{l}\text { Corrected Item - } \\
\text { Total Correlation }\end{array}$ & Kriteria & Ket & Indikator & $\begin{array}{l}\text { Corrected Item - } \\
\text { Total Correlation }\end{array}$ & Kriteria & Ket \\
\hline \multicolumn{4}{|c|}{ Var C. Bonding Social Capital } & \multicolumn{3}{|c|}{ Var D. Bonding Social Capital } & \\
\hline $\mathrm{C} 1$ & 0.617 & 0.22 & Valid & D1 & 0.791 & 0.22 & Valid \\
\hline $\mathrm{C} 2$ & 0.670 & 0.22 & Valid & D2 & 0.613 & 0.22 & Valid \\
\hline $\mathrm{C} 3$ & 0.672 & 0.22 & Valid & D3 & 0.817 & 0.22 & Valid \\
\hline $\mathrm{C} 4$ & 0.813 & 0.22 & Valid & D4 & 0.764 & 0.22 & Valid \\
\hline C5 & 0.801 & 0.22 & Valid & D5 & 0.784 & 0.22 & Valid \\
\hline C6 & 0.695 & 0.22 & Valid & D6 & 0.841 & 0.22 & Valid \\
\hline \multicolumn{4}{|c|}{ Var E. Rural Development } & D7 & 0.672 & 0.22 & Valid \\
\hline $\mathrm{E} 1$ & 0.632 & 0.22 & Valid & D8 & 0.762 & 0.22 & Valid \\
\hline E2 & 0.494 & 0.22 & Valid & & & & \\
\hline E3 & 0.729 & 0.22 & Valid & & & & \\
\hline E4 & 0.848 & 0.22 & Valid & & & & \\
\hline E5 & 0.8 & 0.22 & Valid & & & & \\
\hline E6 & 0.797 & 0.22 & Valid & & & & \\
\hline
\end{tabular}

Sumber: Hasil penelitian.

Uji Reliabilitas dilakukan dengan alpha cronbach dengan SPSS. Uji reliabilitas dilakukan agar angket yang digunakan benarbenar dapat dipercaya sebagai alat pengumpul data. Pada Tabel 5, nilai Alpha sebesar 0.610 di mana nilai distribusi nilai rtabel signifikansi $5 \%$ untuk jumlah responden sebanyak 57, maka didapat nilai rtabel sebesar 0.266. Nilai Alpha > nilai rtabel, maka item-item angket tersebut dapat dipercaya atau reliabel.

\section{Uji Normalitas}

Pengujian normalitas dalam penelitian ini dilakukan dengan menggunakan tes Kolmogorov-Smirnov, dalam tabel berikut akan ditunjukkan hasil dari pengujian tersebut

Tabel 6

Statistik Reliabilitas

\begin{tabular}{cc}
\hline $\begin{array}{c}\text { Cronbach's } \\
\text { Alpha }\end{array}$ & N of Items \\
\hline .610 & 20 \\
\hline
\end{tabular}


Tabel 7

Hasil Uji Normalitas Data

\begin{tabular}{ccc}
\hline $\begin{array}{c}\text { Kolmogorov } \\
\text { Smirnov }\end{array}$ & Asymp. 2 Sig & Keterangan \\
\hline 0,698 & 0,714 & Data Berdistribusi Normal \\
\hline Sumber: Data primer yang diolah peneliti &
\end{tabular}

Berdasarkan hasil uji normalitas data di atas, diketahui bahwa nilai sigfikansi sebesar 0,714, di mana angka tersebut lebih besar dari $\alpha=5 \%$. Sehingga dapat disimpulkan bahwa data yang diuji dalam penelitian ini berdistribusi normal.

\section{Uji Hipotesis}

Dua hipotesis yang ingin dibuktikan dalam penelitian ini adalah: 1) Semakin baik Bonding Modal Sosial maka semakin baik persepsi para remaja berusia 16 - 18 tahun Desa Kifu terhadap TIK untuk pembangunan desanya; 2) Semakin baik Bridging Modal Sosial berdampak buruk terhadap persepsi pelajar SMA Desa Kifu TIK untuk pembangunan desanya. Uji hipotesis dilakukan dengan analisis jalur. Nilai signifikansi dari kedua variabel yaitu $\mathrm{X} 1=$ 0.006 dan $\mathrm{X} 2=0.003$, di mana kedua nilai tersebut kurang dari 0.05. Hal ini berarti bahwa kedua variabel tersebut berpengaruh signifikan terhadap terhadap $\mathrm{Y}$ yang artinya hipotesis 1 dan hipotesis 2 diterima. Variabel Bonding berpengaruh secara positif yakni meningkatkan persepsi fungsi TIK pembangunan desa, sedangkan variabel Bridging sebaliknya yaitu berpengaruh secara negatif yang dapat menurunkan persepsi fungsi TIK dalam pembangunan desanya (Gambar 3).

Tabel 8

Besar Pengaruh Bonding dan Bridging secara Parsial dan Simultan

\begin{tabular}{lcccc}
\hline & $\begin{array}{c}\text { Pengaruh } \\
\text { Langsung }\end{array}$ & $\begin{array}{c}\text { Pengaruh Tidak Langsung, } \\
\text { Melalui }\end{array}$ & $\begin{array}{c}\text { Total } \\
\text { Pengaruh }\end{array}$ \\
\hline Bonding (X1) & $11.63 \%$ & - & $\mathbf{X 2}$ & \\
$\begin{array}{l}\text { Bridging (X2) } \\
\text { Total pengaruh simultan X1 dan X2 }\end{array}$ & $4.12 \%$ & - & $15.75 \%$ \\
Pengaruh Variabel Lain & & & & $33.26 \%$ \\
Total & & & & $66.74 \%$ \\
\hline
\end{tabular}

Sumber: Hasil Penelitian

Besar pengaruh Bonding (15,75\%) lebih kecil dibandingkan dengan pengaruh Bridging (17,51\%). Besarnya nilai R2 atau R Square adalah sebesar 0.332. Hal ini menunjukkan bahwa kontribusi atau sumbangan pengaruh $\mathrm{X} 1$ dan $\mathrm{X} 2$ terhadap $\mathrm{Y}$ adalah sebesar 33,2\% sementara sisanya $66.8 \%$ merupakan kontribusi dari variabelvariabel lain yang tidak dimasukkan ke dalam penelitian ini.

\section{HASIL PENELITIAN DAN PEMBAHASAN}

\section{Karakteristik Responden}

Seluruh responden penelitian ini adalah pelajar SLTA yang tinggal di Desa Kifu dengan rentang usia 16-18 tahun dengan jumlah mencapai 57 orang. Dari persentasi, hampir seluruh responden memiliki perangkat TIK (93\%): handphone $2 \mathrm{G}$ (perangkat selular yang memiliki fitur SMS dan telepon) yaitu $61.4 \%$, disusul ponsel pintar (smartphone yang dapat tersambung dengan internet) sebanyak $35.1 \%$. 


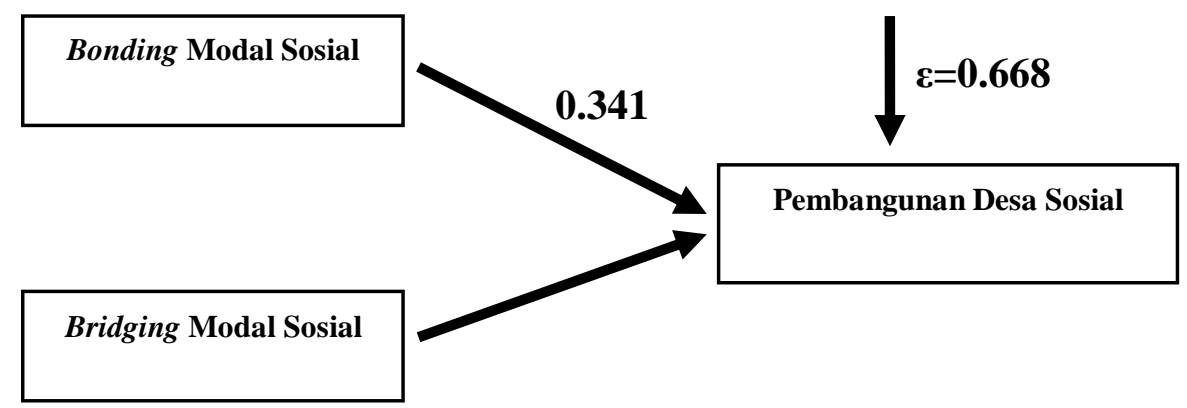

Gambar 3. Koefisien Jalur Pengaruh Variabel X1 dan X2 terhadap Y

Dilihat dari sisi penggunaan perangkat TIK, maka handphone $2 \mathrm{G}$ paling banyak digunakan yakni sebesar $64.9 \%$, disusul kemudian komputer/laptop/PC sebanyak 50.9\%. Penetrasi internet di Desa Kifu, meskipun infrastruktur broadband di tempat ini masih terbilang minim, cukup tinggi. Hal ini terlihat dari banyaknya responden yang mengakses internet yaitu $77.2 \%$. Frekuensi mengakses internet pun cukup tinggi yaitu selama kurang dari dua jam (57.9\%) dan 2 - 4 jam (40.4\%).

Tabel 9

Profil Responden

\begin{tabular}{|c|c|c|}
\hline Profil Responden & Item & Frekuensi \\
\hline \multirow[t]{2}{*}{ Jenis Kelamin } & Laki-Laki & $47.4 \%$ \\
\hline & Perempuan & $52.6 \%$ \\
\hline \multirow{6}{*}{ Kepemilikan Perangkat TIK* } & Ya & $93 \%$ \\
\hline & Tidak & $4 \%$ \\
\hline & Handphone $2 \mathrm{G}$ & $61.4 \%$ \\
\hline & Smartphone 3G & $35.1 \%$ \\
\hline & Komputer/Laptop/PC & $8.8 \%$ \\
\hline & Tablet & $1.8 \%$ \\
\hline \multirow{6}{*}{ Penggunaan Perangkat TIK* } & $\mathrm{Ya}$ & $96.5 \%$ \\
\hline & Tidak & $3.5 \%$ \\
\hline & Handphone $2 \mathrm{G}$ & $64.9 \%$ \\
\hline & Smartphone $3 \mathrm{G}$ & $36.8 \%$ \\
\hline & Komputer/Laptop/PC & $50.9 \%$ \\
\hline & Tablet & $1.8 \%$ \\
\hline \multirow[t]{2}{*}{ Mengakses Internet } & $\mathrm{Ya}$ & $77.2 \%$ \\
\hline & Tidak & $22.8 \%$ \\
\hline \multirow{4}{*}{ Lama Akses Internet } & $>10$ jam & $1.8 \%$ \\
\hline & 5-9 jam & $0.0 \%$ \\
\hline & $2-4$ jam & $40.4 \%$ \\
\hline & $<2$ jam & $57.9 \%$ \\
\hline \multicolumn{3}{|l|}{ Aktivitas menggunakan Internet* } \\
\hline \multirow{5}{*}{\multicolumn{2}{|c|}{$\begin{array}{l}\text { - Mengakses media sosial. } \\
\text { - Membuat, mengirim dan menerima email. } \\
\text { - Bermain game online. } \\
\text { - Mengerjakan tugas sekolah. } \\
\text { - Jual beli online. }\end{array}$}} & $36.8 \%$ \\
\hline & & $22.8 \%$ \\
\hline & & $10.5 \%$ \\
\hline & & $28.1 \%$ \\
\hline & & $1.8 \%$ \\
\hline \multicolumn{3}{|c|}{ *jawaban lebih dari satu } \\
\hline \multicolumn{3}{|l|}{ Sumber: Hasil penelitian } \\
\hline
\end{tabular}


Dari 57 responden tersebut, hanya $37 \%$ atau 21 responden yang pernah mendengar program "Desa Broadband Terpadu" di desanya (Gambar 4). Dari 21 responden tersebut, sebanyak 95\% responden pernah menggunakan fasilitas DBT (Gambar 5) serta $76 \%$ yang memiliki persepsi bahwa fasilitas DBT akan berdampak langsung terhadap pengembangan komunitas di desa (Gambar 6). Temuan ini mengindikasikan bahwa sosialisasi program DBT ini masih perlu ditingkatkan agar masyarakat khususnya kaum remaja atau pelajar dapat menggunakan fasilitas ini untuk meningkatkan pengetahuannya serta kecakapannya.

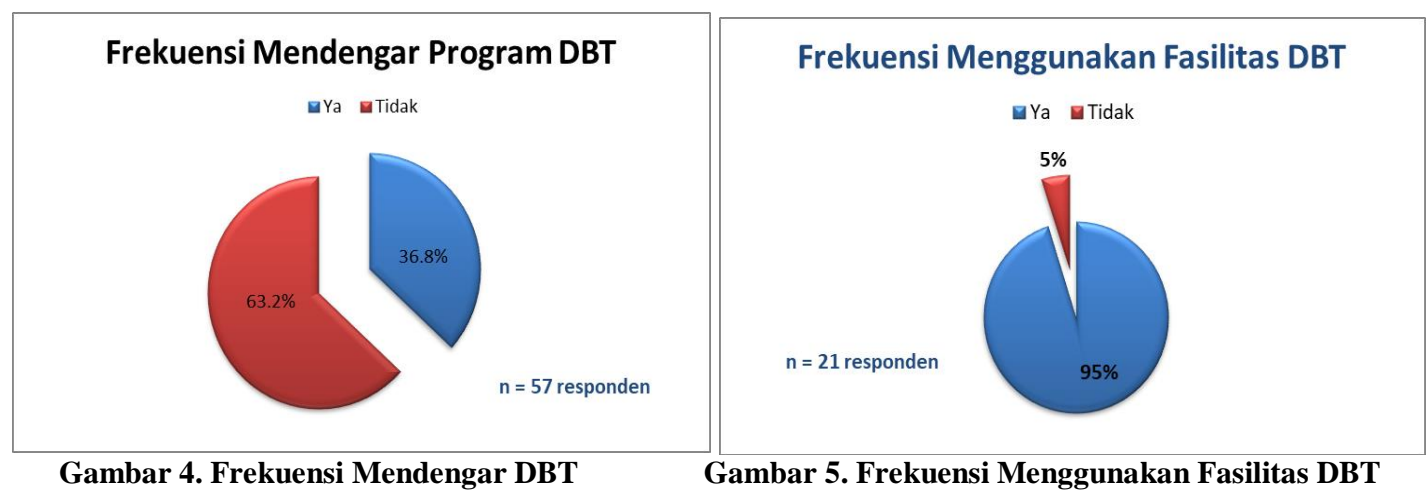

Gambar 4. Frekuensi Mendengar DBT

Gambar 5. Frekuensi Menggunakan Fasilitas DBT

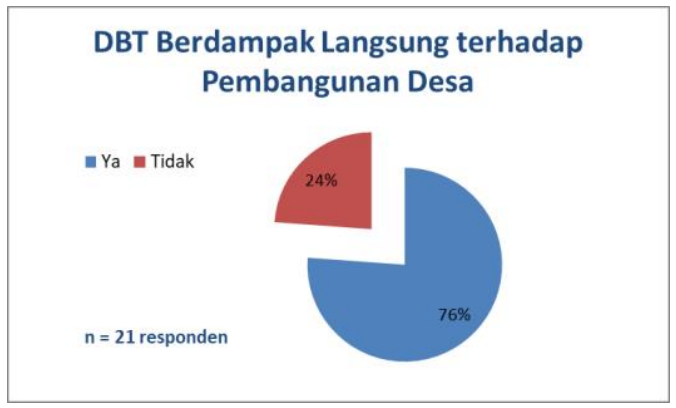

Gambar 6. Persepsi terhadap Dampak DBT terhadap Pembangunan Desa

Keberhasilan pembangunan di desa tidak hanya dipengaruhi semata-mata oleh infrastruktur fisik semata. Tetapi juga, keberhasilan pembangunan dipengaruhi oleh sumber daya manusia yang mengelola infrastruktur tersebut untuk kepentingan kesejahteraan masyarakat desa. Infrastruktur juga tidak saja memfasilitasi kerja sama antaranggota masyarakat desa, tetapi juga antarwarga desa dengan desa lain. Bonding modal sosial, secara definitif, merupakan modal penguat antarindividu di dalam sebuah kelompok. Sementara, bridging modal sosial, secara konseptual, merupakan modal untuk membangun jaringan dengan kelompokkelompok lain yang lebih beragam. Secara logis, kerja sama tidak saja memerlukan bonding antaranggota masyarakat desa, tetapi juga bridging dengan orang-orang di luar desanya. Di era komunikasi yang termediasi dengan TIK ini, modal sosial baik bonding maupun bridging memerlukan apa yang disebut Chew dan koleganya sebagai "dual mechanism" (Ei Chew et al., 2011). Artinya bahwa TIK, khususnya social networking, dapat membesarkan dan mengecilkan kapital sosial secara simultan, yaitu di satu sisi internet dapat meningkatkan partisipasi warga desa untuk pembangunan komunitasnya di desa (co. kegiatan sukarelawan). Namun di sisi lain, penggunaan media jejaring sosial juga dapat mengurangi intensitas hubungannya dengan anggota komunitas lain secara offline.

Hasil statistik penelitian ini menemukan bahwa baik bonding maupun bridging Modal Sosial berdampak signifikan terhadap persepsi para remaja usia 16 - 18 tahun terhadap dampak TIK pada pembangunan desa, meskipun kurang dari 37\%. Persentase 
sisanya mengindikasikan adanya faktor-faktor lain di luar modal sosial yang memengaruhi persepsi para remaja tersebut terhadap TIK dan dampaknya bagi pembangunan desa dan nilainya cukup tinggi yakni sekitar $67 \%$. Faktor keyakinan diri ketika menggunakan internet bisa menjadi salah satu faktor nonmodal sosial. Dalam surveinya di empat wilayah desa di Amerika Serikat, Gregg dan koleganya menemukan bahwa efikasi diri berpengaruh pada penggunaan internet serta ekspektasi hasil secara sosial (Gregg et al., 2007). Efikasi diri adalah keyakinan individu mengenai kemampuan dirinya dalam melakukan tugas atau tindakan tertentu untuk mencapai hasil tertentu. Jika individu yakin mendapat dukungan sosial secara online dengan mudah, maka individu tersebut memiliki bonding yang kurang dengan komunitasnya (Gregg et al., 2007). Chew dan koleganya menemukan bahwa efikasi diri secara online (online self efficacy) dan bonding modal sosial menjadi mediator antara penggunaan media jejaring sosial dengan partisipasi komunitas (community involvement) (Ei Chew et al., 2011). Hal ini berarti kembali kepada individu para remaja tersebut apakah menggunakan TIK untuk meningkatkan pemahamannya terkait komunitas sendiri atau menggunakan TIK untuk membangun jaringan dengan orang lain di luar desanya.

Modal manusia (human capital) juga merupakan faktor lain yang berpengaruh pada eksistensi modal sosial dengan persepsi fungsi TIK untuk pembangunan desa. Díaz Andrade dan Urquhart menemukan bahwa orang desa yang aktif berpartisipasi dan membangun jaringan di luar desa, akan dapat memanfaatkan TIK dengan baik (Díaz Andrade \& Urquhart, 2009). Tidak hanya itu, literasi TIK - khususnya informasi dan komputer - juga memengaruhi pembangunan desa di mana individu dengan literasi yang baik memungkinkan dia untuk mencari informasi serta mendiseminasikan informasi yang berguna bagi anggota komunitasnya. Dua variabel ini - efikasi diri dan modal manusia - dapat digunakan untuk menganalisa dimensi sosial pembangunan infrastruktur di desa.

\section{PENUTUP}

\section{Simpulan}

Penelitian ini merupakan studi empiris dengan pendekatan kuantitatif untuk menggali persepsi terkait dampak modal sosial (bridging modal sosial dan bonding modal sosial) terhadap persepsi TIK bagi pembangunan desa para remaja yang tinggal di wilayah perbatasan. Dalam hal ini lokus penelitian terletak di Desa Kifu, Kupang, Provinsi Nusa Tenggara Timur, yang berbatasan dengan Timor Leste. Hasil statistik menyatakan hipotesis diterima yang artinya bahwa Bridging dan Bonding Modal Sosial memiliki pengaruh yang signifikan terhadap persepsi TIK bagi pembangunan desa. Namun, keduanya bukanlah faktor determinan utama dikarenakan $r$-square di bawah $50 \%$.

\section{Saran}

Kelemahan penelitian ini adalah variabel-variabel determinan persepsi remaja terhadap TIK dan dampaknya bagi pembangunan di desa, selain modal sosial (bridging dan bonding modal sosial), belum tampak dalam penelitian ini. Meski demikian, penelitian ini menganjurkan adanya penelitian serupa di masa yang akan datang, dengan melibatkan variabel efikasi diri dan modal manusia (human capital). Metode penelitian campuran kuantitatif dan kualitatif dapat digunakan untuk menggali informasi lebih dalam terkait faktor determinan persepsi remaja desa terhadap TIK dan dampaknya bagi pembangunan di wilayahnya.

\section{DAFTAR PUSTAKA}

Al Ayyubi, S. (2016) Kominfo Targetkan 500 Desa Terkoneksi Solusi Broadband. [Online]. 2016. Bisnis.com. Available from: http://industri.bisnis.com/read/20160803/10 1/571466/kominfo-targetkan-500-desaterkoneksi-solusi-broadband [Accessed: 3 November 2017].

Balai Penyedia dan Pengelola Pembiayaan Telekomunikasi dan Informatika (2016) Desa Broadband Terpadu, Dari Kominfo untuk Persatuan Indonesia. [Online]. 2016. 
Available

from:

https://bp3ti.kominfo.go.id/news/update/6

[Accessed: 3 November 2017].

Billett, P. (2012) Indicators of youth social capital: The case for not using adult indicators in the measurement of youth social capital. Youth Studies Australia. [Online] 31 (2), 9-16. Available from: https://search.informit.com.au/documentSu mmary; $\mathrm{dn}=511576468098891$;res=IELHSS.

Bourdieu, P. (1986) The Forms of Capital. [Online]. 1986. Available from: https://www.marxists.org/reference/subject/ philosophy/works/fr/bourdieu-formscapital.htm [Accessed: 17 April 2018].

Desa Kifu (2016) Rencana Pembangunan Jangka Menengah Desa Kifu Tahun 2016-2019.

Díaz Andrade, A.E. \& Urquhart, C. (2009) The value of extended networks: Social capital in an ICT intervention in rural Peru. Information Technology for Development. [Online] 15 (2), 108-132. Available from: doi:10.1002/itdj.20116.

Ei Chew, H., LaRose, R., Steinfield, C. \& Velasquez, A. (2011) THE USE OF ONLINE SOCIAL NETWORKING BY RURAL YOUTH AND ITS EFFECTS ON COMMUNITY ATTACHMENT. Information, Communication \& Society. [Online] 14 (5), 726-747. Available from: doi:10.1080/1369118X.2010.539243.

Gatsha, G. \& Masalela, R.K. (2012) Managing and Enhancing ICT Uptake in Rural Communities in Botswana. In: Cases on Developing Countries and ICT Integration. [Online]. IGI Global. pp. 211-217. Available from: doi:10.4018/978-1-60960117-1.ch019.

Gregg, J.L., Larose, R., Straabhauer, J. \& Strover, S. (2007) Resolving One Internet Paradox While Revealing Another: Understanding Online Social Support in Rural America. 57th Annual Conference of the International Communication Association.

Guo, Y., Li, Y. \& Ito, N. (2014) How do different internet use functions affect bridging and bonding social capital? An empirical study of the Chinese international students in Japan. International Journal of Cyber Society and Education. [Online] 7 (1), 7188. Available from: doi:10.7903/ijcse.1074.

Hamel, J.-Y. (2010) ICT4D and the Human Development and Capabilities Approach: The Potentials of Information and Communication Technology. [Online]. Available from: http://hdr.undp.org/sites/default/files/hdrp_2 010_37.pdf.

Hamjen, H. (2016) Analisis Efektivitas Perangkat pada Program Desa Broadband Terpadu [Analysis of Device Effectiveness in Integrated Broadband Village Program]. Buletin Pos dan Telekomunikasi. [Online] 14 (2), 95. Available from: doi:10.17933/bpostel.2016.140203.

Harris, R., Jacquemin, A., Ponthagunta, S., Sah, J., et al. (2003) Rural Development with ICTs in Nepal: Integrating National Policy with Grassroots Resourcefulness. The Electronic Journal of Information Systems in Developing Countries. [Online] 12 (1), 112. Available from: doi:10.1002/j.16814835.2003.tb00079.x.

Kementerian Komunikasi dan Informatika (2015) Desa Broadband Terpadu. [Online]. 2015. Available from: https://kominfo.go.id/index.php/content/deta il/5432/Siaran+Pers+No.62-PIH-

KOMINFO-08-

2015+tentang+Desa+Broadband+Terpadu/0/ siaran_pers [Accessed: 3 November 2017].

Kusumastuti, A. (2016) Modal Sosial dan Mekanisme Adaptasi Masyarakat Pedesaan dalam Pengelolaan dan Pembangunan Infrastruktur. MASYARAKAT: Jurnal Sosiologi. [Online] 20 (1), 1-17. Available from: doi:10.7454/mjs.v20i1.4740.

Nagy, S. (2017) The Impact Of Country Of Origin In Mobile Phone Choice Of Generation Y And Z. Journal of Management and Training for Industries. [Online] 4 (2), 16-29. Available from: doi:10.12792/JMTI.4.2.16.

Putnam, R.D. (2000) Bowling Alone: The Collapse and Revival of American Community. New York, Simon \& Schuster.

Sørensen, J.F.L. (2016) Rural-Urban Differences in Bonding and Bridging Social Capital. Regional Studies. [Online] 50 (3), 391-410. Available from: doi:10.1080/00343404.2014.918945.

Sugiyono (2006) Metode Penelitian Kuantitatif, Kualitatif dan $R \& D$. Bandung, Alfabeta.

Usman, S. (2016) Pengembangan Desa Broadband Terpadu. Jurnal Ilmu Komunikasi. [Online] 14 (3), 189-198. Available from: http://jurnal.upnyk.ac.id/index.php/komunik asi/article/view/2130.

Wiesinger, G. (2007) The importance of social capital in rural development, networking and decision-making in rural areas. Revue de géographie alpine. [Online] (95-4), 43-56. Available from: doi:10.4000/rga.354. 
Williams, D. (2006) On and Off the 'Net: Scales for Social Capital in an Online Era. Journal of Computer-Mediated Communication.
[Online] 11 (2), 593-628. Available from: doi:10.1111/j.1083-6101.2006.00029.x. 